\title{
Resilience and related factors as predictors of relapse risk in patients with substance use disorder: a cross-sectional study
}

\author{
Ayako Yamashita ${ }^{1 *} \mathbb{D}$, Shin-ichi Yoshioka ${ }^{2}$ and Yuki Yajima ${ }^{3}$
}

\begin{abstract}
Background: Resilience, referring to the inherent ability to naturally recover in the face of adverse conditions, is an essential concept in discussions of substance use disorder (SUD) recovery. This study's objective was to shed light on resilience and related factors that affect relapse risk in patients with SUDs.

Method: Fifty-two patients with SUDs were given a self-administrated questionnaire from February to April 2015 consisting of question items for sociodemographic characteristics, relapse risk (Stimulant Relapse Risk Scale), and resilience (Bidimensional Resilience Scale). Scale scores were tested for associations with subject attributes, after which resilience's effects on relapse risk were analyzed using correlation and multiple regression (forced-entry) analyses.

Results: Stimulants were the most common substance related to SUD ( $n=26,21.7 \%$; multiple answers). Bivariate correlation showed that higher acquired resilience was significantly associated with a lower relapse risk $(r=-0.314$, $P<0.01$ ). Reduced relapse risk was significantly associated with current employment (Std. $\beta=-0.446, P<0.05$ ).

Conclusion: Our findings demonstrate the necessity of recovery support to enhance acquired resistance in patients with SUDs to prevent relapses. Reinforcing employment support services and encouraging patients to continue treatment were suggested as potentially effective measures to enhance resilience in individuals with SUDs on their road to recovery.
\end{abstract}

Keywords: Resilience, Recurrence, Substance use disorder, Employment, Recovery

\section{Introduction}

Substance use disorders (SUDs) are a group of mental illnesses characterized by impulsive behavior and a persistent, strong desire to ingest a given substance that are associated with drug-seeking behavior, withdrawal symptoms, and tolerance [1].

SUDs can involve a wide variety of drugs, including stimulants, analgesics, hypnotics, and narcotics [2]; potential for mental and/or physical dependence depends

\footnotetext{
* Correspondence: aya-yama@health.nop.kagoshima-u.ac.jp

${ }^{1}$ Faculty of Medicine, School of Health Sciences, Kagoshima University, 8-35-1 Sakuragaoka, Kagoshima 890-8544, Japan

Full list of author information is available at the end of the article
}

in part on the substance's mechanism of action. According to 2017 estimates, 2.3\% of Japan's population have experience a SUD at least once in their lives. Cannabis is the most commonly used substance, with an estimated lifetime prevalence of $1.4 \%$ [3]. According to a 2016 factfinding survey regarding the number of patients with SUDs in Japan [4], among the 2262 patients either hospitalized or receiving outpatient treatment at psychiatric facilities, 1209 (53.4\%) were addicted to amphetamines, followed by $384(17.0 \%)$ that were addicted to sleeping pills or tranquilizers. Thus, in psychiatric treatment settings in Japan, the principal issue is drug-related disorders related to amphetamine use. However, some 
commentators have called for an urgent overhaul of Japan's SUD treatment system, noting the paucity of facilities dedicated to drug rehabilitation and the resulting low rates of treatment among those who need it [5].

Studies have raised cognitive-behavioral therapy (CBT) and stage-transition models as effective interventions for drug dependence [6] and demonstrated the importance of self-awareness and its association with drug cessation [7]. Coping skills, recreational activities, and social support have been reported to effectively encourage continued abstinence [8].

Drug dependence can be considered a chronic disease based on its pathology and symptoms, meaning patients with SUDs should be provided with continuous therapy and support even after they have stopped taking the offending substance. Moreover, since denial is a characteristic symptom of drug dependence [9], it is imperative for patients to gain self-management skills by deeply understanding their disease and personally feeling the benefits of recovery.

Resilience is a concept that has attracted attention in recent years in discussions about recovery from substance dependence [10]. Resilience is the ability to adapt to adverse conditions [11-13], and it is regarded in the field of psychiatry as a critical component of recovery. Resilience does not reflect personal weakness; it can be enhanced in anyone and everyone [14]. Resilience can be subcategorized into innate resilience, a product of inherent, individual factors, and acquired resilience, which can be modified and strengthened by a variety of environmental factors $[15,16]$.

Some SUD treatment approaches are based on selfmedication theory [17], which hypothesizes that one of the main motives for using illegal substances is that they offer potential temporary relief from psychological distress stemming from chronic sensory overload [18]. The most recent learning and habit theories of addiction posit that drug addiction can be understood in terms of normal learning and memory neuronal systems, which, through chronically self-administered drug actions, are pathologically subverted, thereby leading to the establishment of compulsive drug-seeking habits [19]. Furthermore, because the use of illicit drugs can seriously disrupt a person's self-control and self-efficacy, it is important to provide people with SUD with support that can increase their resilience and self-esteem [20]. For this population, social support and resilience have been shown to mediate the effects of stress on life satisfaction [21].

Participation in recovery group meetings held in selfhelp groups and treatment centers helps with SUD by improving self-disclosure [22]. Self-help group participation can constitute a "spiritual" experience, enhancing self-disclosure [23] and allowing attendees to recognize their own experiences in the stories of others [24]. This strengthens resilience, a crucial psychological trait for preventing relapse. This trait is crucial to the concept of recovery as it relates to people with mental disorders. Recovery has been defined as "a process that allows people (with diseases or disabilities) to actively participate in their life, work, study, and community; affected individuals may conceptualize it as the ability to lead a rich and productive life despite their disability, whereas others may see it as a reduction or mitigation of those individuals' symptoms" [25]. While individual factors certainly play a role in SUD recovery, it is acquired resilience-related factors that are predicted to strongly drive recovery, helping people to grow and develop as they combat their disease.

It has been shown that, to prevent relapse in people with alcohol use disorders (AUDs), attending group meetings sponsored by self-help groups and treatment facilities can help individuals attain deeper levels of selfdisclosure, which has been associated with greater resilience [26]. That should also apply in the case of SUDs. Although it is known from previous studies that resilience needs to be increased to prevent SUD relapse, the relationship between resilience and the relapse risk remains unclear.

The purpose of this study was to test the hypothesis that if resilience improved in patients with SUDs who attended a self-help group, their relapse risk would be lower. Showing how resilience may be related to the relapse risk should lead to better recovery support for patients with SUDs.

\section{Methods}

Study design

This study used a cross-sectional design.

\section{Study sample}

The managers of three drug addiction rehabilitation centers and one medical center specializing in the treatment of substance dependence that sponsored self-help support groups in the Chugoku or Kinki regions of Japan agreed to participate in the study after receiving both verbal and written explanations of the study. The sample consisted of drug-dependent patients attending self-help support groups at these facilities and who consented to participate. Self-help groups had a facilitator trained in evidence-based treatments.

\section{Data collection}

Data were collected using an anonymous selfadministered questionnaire. Each facility was asked to distribute and collect the questionnaires and to determine who should be asked to participate. The study took place from February through March 2015. The facilities were provided with 80 questionnaires. After completing 
the survey, respondents put the questionnaire in a sealed envelope that they deposited in a collection box set up at each facility. One month later, representatives at each facility mailed the surveys to the researchers. A total of 52 responses were received (response rate: 65\%).

\section{Demographics}

Demographic features asked about in the questionnaire were as follows: age, gender, whether they lived with another person or had a key person with whom to consult in their lives, employment status, age when diagnosed with SUD, treatment time period (estimated lifetime total), abstinence period, the number of sessions and time period participating in self-help groups, the types of dependence drugs, other psychological disorders, and physical disorders.

\section{Resilience}

This study used the Bidimensional Resilience Scale developed in Japan [27, 28]. This scale comprises innate resilience factors (12 questions related to individual factors) and acquired resilience factors (9 questions related to environmental factors). The innate resilience factors indicate those that are strongly related to the individual's inherent nature; acquired factors indicate learned methods of resilience. The innate resilience factors included optimism, control, sociability, and vitality; acquired resilience factors included attempting to solve a problem, self-understanding, and understanding others. This scale uses a five-point rating for the questionnaire, with higher total scores indicating greater resilience. In this study, the Cronbach's $\alpha$ coefficient for the Bidimensional Resilience Scale was 0.797; thus, internal consistency was maintained.

\section{Stimulant relapse risk}

To measure the risk of SUD relapse, we used the Stimulant Relapse Risk Scale (SRRS) [29]. This scale consists of 30 items on 5 subscales as follows: anxiety and intention to use drugs (AI); emotionality problem (EP); compulsivity for drugs $(\mathrm{CD})$; positive expectancies and lack of control over drugs (PL); and lack of negative expectancy for drugs (NE). The SRRS includes five items to measure insight into mental condition: awareness of illness (AI). Examples of the items are "The feeling I used to have while using the drug sometimes comes back" (AI); "I feel a constant need to put something in my mouth" (EP); "I would do almost anything in order to use the drug" (CD); "I would use the drug if I were alone" (PL); and "I would not be able to control myself if I use the drug" (NE). Higher average scores for total and subscale items indicate higher relapse risk, and this study only used the total score. All items ask about a drug-related situation in the past 1 week. When 5 supplementary items indicating the respondent's intensity of awareness of their illness were included, this scale consisted of a total of 35 items. Questions used a threestep rating scale, with higher scores indicating a greater risk of using the drug of dependence. In this study, the Cronbach's $\alpha$ coefficient for the 35 items in the SRRS was 0.883 ; thus, internal consistency was maintained.

\section{Statistical analysis}

First, resilience and SRRS score distributions were tested for normality using the Shapiro-Wilk test. Resilience and relapse risk were then compared between subgroups with different demographic characteristics using the Student's t-test. Next, Pearson product correlation coefficients were calculated among the following variables: current age, age at diagnosis, treatment time period, abstinence period, acquired resilience score, innate resilience score, and SRRS total score. Finally, multiple linear regression analysis via the forced-entry procedure was performed using relapse risk as the dependent variable, innate and acquired resilience as independent variables, and the following control variables: current age, employment status (dummy variable: $1=$ employed, $0=$ unemployed), age at diagnosis, the treatment time period, and the abstinence period. Variance inflation factors were calculated for each independent variable to check for collinearity in multiple regression analysis: each measured < 4.0, indicating minimal multicollinearity. Given the small sample size and considering the nature of the concept of resilience, comorbid mental illness was not included as a control variable. Statistical analyses were performed using IBM SPSS 24.0 J for Windows (SPSS, Chicago, IL), and the significance level was set at $5 \%$ for all tests.

\section{Ethical considerations}

After receiving approval from the Tottori University Faculty of Medicine Ethics Review Committee (approval number 2646), this study was conducted in accordance with the fundamental principles set forth in the Helsinki Declaration. Informed consent was obtained from each participant after the procedure(s) had been fully explained.

\section{Results}

\section{Subject attributes}

Surveys were given to 80 individuals who attended selfhelp support groups at three drug addiction rehabilitation centers and one medical center specializing in the treatment of substance dependence. Surveys were collected from 52 of those individuals (response rate: 65.0\%). Table 1 details their demographics and other attributes. 
Table 1 Demographic characteristics of the sample

\begin{tabular}{|c|c|c|}
\hline Items & Values & $\begin{array}{l}\text { mean } \pm S D \text {, } \\
\text { (Range) }\end{array}$ \\
\hline Number of participants & 52 & \\
\hline Gender (\% male) & 88.5 & \\
\hline Age (years), (Range) & & $37.2 \pm 10.0,(20-66)$ \\
\hline Employment status (\% work) & 32.7 & \\
\hline Presence of key person (\% yes) & 94.2 & \\
\hline Living with someone (\% yes) & 86.5 & \\
\hline \multicolumn{3}{|l|}{ Treatment state $(n)$} \\
\hline Outpatient & 37 & \\
\hline Inpatient & 1 & \\
\hline Untreated & 4 & \\
\hline Cessation of treatment & 3 & \\
\hline Unknown & 7 & \\
\hline $\begin{array}{l}\text { Age when diagnosed with SUD (years), } \\
\text { (Range) }\end{array}$ & & $29.3 \pm 9.4,(15-52)$ \\
\hline Treatment time period (months), (Range) & & $67.0 \pm 68.9,(5-282)$ \\
\hline Abstinence period (months), (Range) & & $31.9 \pm 30.2,(0-132)$ \\
\hline $\begin{array}{l}\text { Number of sessions and time period particip } \\
\text { in self-help groups (weekly) }\end{array}$ & pating & $5.7 \pm 2.0$ \\
\hline Comorbid mental illness ( $n$ ) & & 14 \\
\hline Physical disorders (n) & & 14 \\
\hline
\end{tabular}

$n$ number of participants

Table 2 shows the population's drugs of dependence. Stimulants were the most common substance involved in SUD, and they were taken by 26 subjects (21.7\%; multiple answers).

The study population was actively and continuously participating in treatment: $73.1 \%$ were visiting hospitals or receiving inpatient treatment for SUDs, while the complete sample attended meetings in SUD

Table 2 Types of drugs of abuse among subjects

\begin{tabular}{lll}
\hline Items & $\mathbf{n}$ & \% \\
\hline Stimulant & 26 & 21.7 \\
Alcohol & 18 & 15.0 \\
Prescription drugs & 21 & 17.5 \\
Thinner & 13 & 10.8 \\
Others & 16 & 13.3 \\
$\quad$ Synthetic cannabinoid & 12 & 10.0 \\
Cannabis & 9 & 7.5 \\
Opioid & 1 & 0.8 \\
Cocaine & 1 & 0.8 \\
$\quad$ Methylenedioxymethamphetamine & 1 & 0.8 \\
Marijuana & 1 & 0.8 \\
Lysergic acid diethylamide & 1 & 0.8 \\
\hline
\end{tabular}

Multiple answers

$n$ number of participants rehabilitation centers or self-help groups $5.7 \pm 2.0$ times per week on average. In addition, approximately $90 \%$ were living with someone else or had someone with whom they could talk about their SUD. The average abstinence period was 2 years 8 months. These statistics suggest that our population consisted of individuals receiving continuing treatment for SUDs who maintained good interpersonal relationships and had some form of social support.

The fact that subjects were abstinent for only 2 years 8 months on average despite receiving treatment for approximately 6 years suggests that people with SUDs require a long time to break away from their disease.

\section{Scale scores}

Table 3 presents resilience and relapse risk scale data.

\section{Attributes versus resilience and SRRS scores}

Table 4 contains the results of statistical comparisons between attributes and instrument scores. Relapse risk was significantly lower in employed subjects ( $t$ [43] = 2.976, $P<0.01)$ and those with a comorbid mental illness (t [39] $=2.083, P<0.05)$.

\section{Correlation analysis}

Pearson correlation coefficients were calculated among the following variables: current age, age at diagnosis, treatment time period, abstinence period, and total scores for each scale (Table 5). Current age positively and significantly correlated with age at diagnosis $(r=$ $0.600, P<0.01)$ and treatment time period $(r=0.492$, $P<0.01)$. In addition, treatment time period positively and significantly correlated with the abstinence period $(r=0.367, P<0.01)$. Innate and acquired resilience exhibited a significant correlation as well $(r=0.585, P<$ $0.01)$. The total SRRS score was significantly and negatively correlated with both innate resilience $(r=-0.310$, $P<0.01)$ and acquired resilience $(r=-0.314, P<0.01)$.

\section{Relapse risk-related factors}

Only patients without missing data for scale items were included in this subanalysis $(n=38)$. Multiple regression (forced-entry) analysis was conducted using SRRS total score as the dependent variable and current age, employment status, age at diagnosis, treatment time period, abstinence period, and acquired resilience as independent variables. The model's multiple correlation coefficient (R) was 0.562 (coefficient of multiple determination $\left.\left[R^{2}\right]=0.315\right) \quad(P<0.05)$. Table 6 contains the standard partial regression coefficients between SRRS total score and each independent variable. Reduced relapse risk was significantly associated with current employment (Std. $\beta=-0.446, P<0.05)$. No significant difference was found for acquired resilience (Std. $\beta=-0.382, P<0.05)$. 
Table 3 Average scale scores

\begin{tabular}{|c|c|c|}
\hline Items & mean $\pm S D$ & $\begin{array}{l}(n=52) \\
\text { (Range) }\end{array}$ \\
\hline \multicolumn{3}{|l|}{ Bidimensional Resilience Scale } \\
\hline Innate resilience & $35.3 \pm 7.3$ & $(23-58)$ \\
\hline Acquired resilience & $29.4 \pm 4.7$ & $(20-41)$ \\
\hline \multicolumn{3}{|l|}{ Stimulant Relapse Risk Scale } \\
\hline Anxiety and intention to use drugs & $14.5 \pm 4.0$ & $(8-23)$ \\
\hline Emotionality problem & $16.5 \pm 4.2$ & $(8-24)$ \\
\hline Compulsivity for drugs & $5.5 \pm 2.1$ & $(4-12)$ \\
\hline $\begin{array}{l}\text { Positive expectancies and lack of control over } \\
\text { drugs }\end{array}$ & $13.0 \pm 3.6$ & $(6-8)$ \\
\hline Lack of negative expectancy for the drug & $5.7 \pm 1.9$ & $(4-10)$ \\
\hline Awareness of illness & $11.9 \pm 2.3$ & $(6-15)$ \\
\hline Total & $67.1 \pm 16.5$ & $(43-93)$ \\
\hline
\end{tabular}

$n$ number of participants

\section{Discussion}

Study participants had innate and acquired resilience scores of $35.3 \pm 7.3$ and $29.4 \pm 4.7$, respectively. This study identified the employment status and acquired resilience as two factors significantly associated with relapse risk.

First, our population had innate and acquired resilience scores of $35.3 \pm 7.3$ and $29.4 \pm 4.7$, respectively. A previous study using the same Bidimensional Resilience Scale observed respective scores of $38.2 \pm 8.1$ and $30.1 \pm$ 5.5 in patients with AUDs [26]. While acquired resilience scores did not greatly differ between the two studies, our subjects' innate resilience score was 2.9 points lower. A previous study reported low levels of resilience in individuals with a SUD [30]. This study found no significant difference in the association between relapse risk and innate or acquired resilience (Std. $\beta=-0.382, P<$ $0.05)$. However, there was a significant bivariate correlation showing that the higher the acquired resilience, the lower the relapse risk $(r=-0.314, P<0.01)$. This suggests that resilience is enhanced as patients recover

Table 4 Comparison of attributes resilience scores and relapse risk score

$(n=52)$

\begin{tabular}{|c|c|c|c|c|c|c|c|}
\hline \multirow[t]{3}{*}{ Items } & \multirow{3}{*}{$\mathbf{n}$} & \multicolumn{4}{|c|}{ Bidimensional Resilience Scale } & \multirow{2}{*}{\multicolumn{2}{|c|}{$\begin{array}{l}\text { Stimulant Relapse Risk } \\
\text { Scale }\end{array}$}} \\
\hline & & \multicolumn{2}{|c|}{ Innate resilience factors } & \multicolumn{2}{|c|}{ Acquired resilience factors } & & \\
\hline & & mean $\pm S D$ & $P$ value & mean $\pm S D$ & $P$ value & mean $\pm S D$ & $P$ value \\
\hline \multicolumn{8}{|l|}{$\overline{\text { Sex }}$} \\
\hline Male & 46 & $35.7 \pm 7.5$ & 0.442 & $29.3 \pm 4.6$ & 0.612 & $66.8 \pm 12.4$ & 0.645 \\
\hline Female & 6 & $33.2 \pm 5.3$ & & $30.3 \pm 5.2$ & & $69.6 \pm 14.4$ & \\
\hline \multicolumn{8}{|l|}{ Employment status } \\
\hline Yes & 17 & $37.1 \pm 7.1$ & 0.287 & $29.1 \pm 4.7$ & 0.754 & $60.3 \pm 9.7$ & $0.005^{* *}$ \\
\hline No & 35 & $34.6 \pm 7.3$ & & $29.6 \pm 4.7$ & & $70.9 \pm 12.4$ & \\
\hline \multicolumn{8}{|l|}{ Presence of key person } \\
\hline Yes & 49 & $35.4 \pm 7.4$ & 0.988 & $29.3 \pm 4.7$ & 0.218 & $66.7 \pm 12.2$ & 0.762 \\
\hline No & 2 & $35.5 \pm 6.4$ & & $33.5 \pm 0.7$ & & $64.0 \pm 11.3$ & \\
\hline \multicolumn{8}{|l|}{ Living with someone } \\
\hline Yes & 45 & $35.8 \pm 7.3$ & 0.255 & $29.6 \pm 4.8$ & 0.498 & $66.6 \pm 12.8$ & 0.443 \\
\hline No & 7 & $31.8 \pm 6.6$ & & $28.3 \pm 4.2$ & & $70.8 \pm 10.4$ & \\
\hline \multicolumn{8}{|l|}{ Treatment state } \\
\hline Under medical treatment & 38 & $35.7 \pm 7.6$ & 0.348 & $29.2 \pm 4.6$ & 0.492 & $67.1 \pm 13.8$ & 0.751 \\
\hline Untreated and cessation of treatment & 7 & $34.0 \pm 0.0$ & & $27.0 \pm 0.0$ & & $64.0 \pm 0.0$ & \\
\hline \multicolumn{8}{|l|}{ Comorbid mental illness } \\
\hline Yes & 14 & $37.2 \pm 8.2$ & 0.375 & $29.4 \pm 4.2$ & 0.946 & $60.8 \pm 14.0$ & $0.044^{*}$ \\
\hline No & 33 & $34.9 \pm 7.2$ & & $29.5 \pm 5.0$ & & $68.8 \pm 10.2$ & \\
\hline \multicolumn{8}{|l|}{ Physical disorders } \\
\hline Yes & 14 & $36.1 \pm 6.9$ & 0.795 & $28.4 \pm 3.8$ & 0.431 & $70.0 \pm 14.7$ & 0.430 \\
\hline No & 33 & $35.6 \pm 7.6$ & & $29.8 \pm 4.9$ & & $65.8 \pm 11.5$ & \\
\hline
\end{tabular}

$n$ number of participants

Statistical evaluation is performed by the Student's t-test. ${ }^{*} P<0.5,{ }^{* *} P<0.01$

We have used a pairwise method, so the total number is different 
Table 5 Correlation of the variables

\begin{tabular}{|c|c|c|c|c|c|c|c|}
\hline & & & & & & & $(n=38)$ \\
\hline & $\begin{array}{l}\text { Stimulant Relapse } \\
\text { Risk Scale (total) }\end{array}$ & Age & $\begin{array}{l}\text { Age when diagnosed } \\
\text { with SUD (years) }\end{array}$ & $\begin{array}{l}\text { Treatment time } \\
\text { period (months) }\end{array}$ & $\begin{array}{l}\text { Abstinence } \\
\text { period (months) }\end{array}$ & $\begin{array}{l}\text { Innate } \\
\text { resilience }\end{array}$ & $\begin{array}{l}\text { Acquired } \\
\text { resilience }\end{array}$ \\
\hline $\begin{array}{l}\text { Stimulant Relapse Risk } \\
\text { Scale (total) }\end{array}$ & 1.000 & -0.087 & -0.088 & 0.057 & 0.101 & $-0.310^{* *}$ & $-0.314^{* *}$ \\
\hline Age & -0.087 & 1.000 & $0.600^{* *}$ & $0.492^{* *}$ & 0.189 & -0.040 & 0.130 \\
\hline $\begin{array}{l}\text { Age when diagnosed } \\
\text { with SUD (years) }\end{array}$ & -0.088 & 0.600 & 1.000 & -0.027 & -0.149 & 0.110 & 0.123 \\
\hline $\begin{array}{l}\text { Treatment time period } \\
\text { (months) }\end{array}$ & 0.057 & $0.492^{* *}$ & -0.027 & 1.000 & $0.367^{* *}$ & -0.160 & 0.145 \\
\hline $\begin{array}{l}\text { Abstinence period } \\
\text { (months) }\end{array}$ & 0.101 & 0.189 & -0.149 & $0.367^{* *}$ & 1.000 & -0.007 & -0.180 \\
\hline Innate resilience & $-0.310^{* *}$ & -0.040 & 0.110 & -0.160 & -0.007 & 1.000 & $0.585^{* *}$ \\
\hline Acquired resilience & $-0.314^{* *}$ & 0.130 & 0.123 & $0.145^{* *}$ & -0.180 & $0.585^{* *}$ & 1.000 \\
\hline
\end{tabular}

$n$ number of participants, Pearson's correlation coefficient

Statistical evaluation is performed by the Pearson correlation coefficient. ${ }^{* *} P<0.01$

from SUDs. The idea of a resilience-related mechanism that protects people from psychological risk has empirical support, with findings demonstrating such a mechanism to reduce the effects of said risks, decrease negative chain reactions, and establish and maintain selfesteem and self-efficacy [15]. This indicates that interventions intended to instill self-esteem and self-efficacy in patients during their recovery should primarily involve modifying their environment, such as changing or avoiding interactions with others formerly associated with the SUD and correcting cognitive distortions [31]. Mindfulness's efficacy in correcting cognitive distortions has been demonstrated in patients with SUDs [32]. Recent years have seen the application of workbook-based CBT based on evidence from the Matrix Model in the USA, with proven results [33].
Our findings, that the relapse risk was significantly and negatively correlated with innate and acquired resilience, with high acquired resilience predicting reduced relapse risk, illustrate the need for SUD recovery to focus on enhancing resilience. SUD prevention-related research on resilience has reported that such efforts to improve resilience need to be started in early childhood [34]. Moreover, resilience-related research has demonstrated the need for family-based interventions and social support, showing a community affinity-based intervention program to enhance resilience in families with teenagers-a demographic at high risk for alcohol and drug dependence [35]. This would necessitate programs to improve resilience starting in the teenage years. Moreover, resilience building requires a safe and stable treatment environment, where individuals can self-

Table 6 Relapse risk factors

\begin{tabular}{|c|c|c|c|c|c|c|}
\hline \multirow{3}{*}{ Variable } & \multirow{3}{*}{$\begin{array}{l}\text { Partial regression } \\
\text { coefficient } \\
\text { (B) }\end{array}$} & \multirow{3}{*}{$\begin{array}{l}\text { Standardized Partial regression } \\
\text { coefficient } \\
(\beta)\end{array}$} & \multirow{3}{*}{$\mathbf{T}$} & \multirow{3}{*}{$P$-value } & \multirow{2}{*}{\multicolumn{2}{|c|}{$\begin{array}{l}(n=38) \\
95.0 \% \text { confidence } \\
\text { interval for B }\end{array}$}} \\
\hline & & & & & & \\
\hline & & & & & $\begin{array}{l}\text { Lower } \\
\text { bound }\end{array}$ & $\begin{array}{l}\text { Upper } \\
\text { bound }\end{array}$ \\
\hline Innate resilience & 0.035 & 0.021 & 0.093 & 0.926 & -0.737 & 0.808 \\
\hline Acquired resilience & -1.125 & -0.382 & -1.709 & 0.098 & -2.469 & 0.219 \\
\hline Age (year) & -0.371 & -0.234 & $-\overline{0} \cdot 934$ & 0.358 & -1.183 & 0.440 \\
\hline $\begin{array}{l}\text { Employment status (Dummy variable: } \\
\text { Yes 1, No 0) }\end{array}$ & -12.148 & -0.446 & -2.648 & $0.013^{*}$ & -21.515 & -2.780 \\
\hline Age when diagnosed with SUD (year) & 0.182 & 0.106 & 0.476 & 0.637 & -0.598 & 0.961 \\
\hline Treatment time period (month) & 0.040 & 0.224 & 1.034 & 0.310 & -0.039 & 0.119 \\
\hline Abstinence period (month) & 0.044 & 0.101 & 0.558 & 0.581 & -0.117 & 0.205 \\
\hline \multicolumn{7}{|l|}{$R^{2}=0.306$, Adjusted $R^{2}=0.145$} \\
\hline
\end{tabular}

$n$ number of participants,

Statistical evaluation is performed by multiple regression analysis. ${ }^{*} P<0.05$

Dependent variable is SRRS Stimulant Relapse Risk Scale (total) 
disclose with peace of mind. Other research has reported resilience to be enhanced through better self-disclosure by participation in meetings held in self-help groups and treatment centers aimed at preventing relapse in alcohol dependence [36].

Substance dependence must be treated using a dual approach-targeting withdrawal symptoms due to physical dependence as well as drug-seeking behavior due to mental dependence [37]. In addition, continuous therapy combining pharmacological with psychosocial interventions is essential for SUD recovery. We found that subjects with a comorbid mental illness were at a significantly lower relapse risk than those without ( $t$ [39] $=2.083, P<0.05)$ : Perhaps the fact that these individuals had already been receiving continued treatment is in part responsible.

We identified ongoing employment as a factor related to relapse risk. This finding could also be explained by subjects gaining employment as a result of reduced relapse risk. Employment is a form of self-actualization, which leads to improved self-esteem and self-efficacy. Employment can be equally conceived of as a desire to engage with the recovery process, a form of empowerment, a sign of taking personal responsibility, and as a significant role in someone's life [38]. Employment history, marketable skills, and barriers have all been identified as essential elements of vocational assessments for patients with SUDs performed in SUD treatment programs [39]. Punishments for illegal drug use and difficulties with living impairment due to dependence can cause people to leave their jobs. However, employment's association with acquired resilience shows the need for recovery programs to incorporate vocational support, tailored to a patient's stage in the recovery process. Selfstigma has negative effects on self-esteem and selfefficacy and a continuing impact on wellbeing [40]. However, self-stigma can be reduced by attending a selfhelp group. In addition, it has been shown that outpatients with SUDs who attended a self-help group and also received psychotherapy had increased employment opportunities and an improved prognosis [41]. Although, for the sample in this study, there were no significant differences in how long participants had been attending a self-help group or in how many sessions they attended that affected acquired resilience and relapse risk; it appeared that attendance had a positive effect on selfesteem and self-efficacy and increased the chances of employment. Getting a job is not something that happens without social support. In SUD recovery support interventions, such as Individual Placement and Support [42], it is important in interactions with patients to promote acquired resilience by trusting the patient, believing in their potential and communicating the hope that they can work (general employment), even if they have a disability. This study showed, for the first time, that being employed may be related to the reduction of SUD relapse risk. Employment support services for individuals with SUDs should be reinforced as a community-based measure to support their recovery.

The sample is small; only 80 surveys were distributed because it is difficult to reach this population in large numbers. This study's cross-sectional design prevents us from drawing inferences about the recovery process over time in individuals with SUDs. In addition, given the small sample size, our findings may not necessarily capture all facets of SUDs at the population level. Multiple regression analysis may have shown no significant difference between the regression risk and acquired resilience due to the small sample size. Furthermore, there may be individual differences in certain respects, such as how quickly and severely dependence forms, given the great variation in SUD, and, accordingly, their biological and psychoactive properties. Conducting a longitudinal study to shed light on how resilience changes during the recovery process is a task for future studies.

\section{Conclusion}

Our findings provide some insight into the therapeutic benefits of recovery support of patients with SUD. Greater acquired resilience was correlated with lower relapse risks $(r=-0.314, P<0.01)$; furthermore, reduced relapse risk was significantly associated with current employment (Std. $\beta=-0.446, P<0.05$ ).

The association of acquired resilience with employment status means that recovery programs need to incorporate employment support tailored to patients' progress in the recovery process. Recovery support to enhance resilience in individuals with SUDs should include means to improve employment support services and ensure that patients continue treatment in the long term.

\section{Abbreviations \\ Al: Anxiety and intention to use drug; Al: Awareness of illness; CBT: Cognitive-behavioral therapy; CD: Compulsivity for drug; EP: Emotionality problem; N: Number of participants; NE: Lack of negative expectancy for the drug; PL: Positive expectancies and lack of control over drug; SD: Standard deviation; SRRS: Stimulant Relapse Risk Scale; SUDs: Substance use disorders}

\section{Acknowledgements}

We would like to express our sincerest heartfelt gratitude to everyone who has cooperated with this study.

\section{Authors' contributions}

Conception and design of the study: A.Y. and S.Y. Acquisition and analysis of data: A.Y., S.Y., and Y.Y. Drafting of the manuscript and table: A.Y., S.Y., and Y.Y. All authors gave substantial contribution to and agreement on the final version of the manuscript.

Authors' information

Not applicable. 


\section{Funding}

This study was completed as a part of the research conducted via the Grantin-Aid for Scientific Research (C) (Grant Number 15 K11835).

\section{Availability of data and materials}

The data analyzed in the current study are not publicly available due to confidential and potentially sensitive information. Data are available from the corresponding author on request.

\section{Declarations}

\section{Ethics approval and consent to participate}

After receiving approval from the Tottori University Faculty of Medicine Ethics Review Committee (approval number 2646), this study was conducted in accordance with the fundamental principles set forth in the Helsinki Declaration. Informed consent was obtained from each participant after the procedure(s) had been fully explained.

\section{Consent for publication}

The authors have obtained consent to publish from the participants.

\section{Competing interests}

The authors declare that they have no competing interests.

\section{Author details}

${ }^{1}$ Faculty of Medicine, School of Health Sciences, Kagoshima University, 8-35-1 Sakuragaoka, Kagoshima 890-8544, Japan. ${ }^{2}$ Faculty of Medicine, School of Health Science, Tottori University, Yonago, Japan. ${ }^{3}$ Department of Nursing, Faculty of Human Health Sciences, Niimi University, Niimi, Japan.

\section{Accepted: 21 April 2021}

Published online: 04 May 2021

\section{References}

1. World Health Organization. International statistical classification of diseases and related health problems 10th revision, ICD-10 version. 2016. https://icd. who.int/browse10/2016/en\#. Accessed 20 Aug 2020.

2. American Psychiatric Association. Diagnostic \& Statistical Manual of mental disorders. 5th ed. Washington: American Psychiatric Association Publishing: 2013. https://doi.org/10.1176/appi.books.9780890425596.

3. Shimane T, Qiu D, Wada K. Nationwide general population survey on drug use in Japan. In: Shimane T, editor. Monitoring survey on substance use disorder and recovery support for substance use disorder and their families: Annual report of Ministry of Health, Labour and Welfare; 2017. p. 7-134. https://www.ncnp.go.jp/nimh/yakubutsu/report/pdf/J_NGPS_2017.pdf (in Japanese). Accessed 18 Aug 2020.

4. Matsumoto T, Ito T, Takano A, Tanibuchi Y, Funada D, Tachimori H. Survey on substance-related psychiatric diseases in Japanese psychiatric facilities. In: Shimane T, editor. 2016 Ministry of Health, Labour and Welfare grants-inaid for scientific research, research on regulatory science of pharmaceuticals and medical devices, annual report on the current status of illicit and designer drug abuse and dependency and interventions to promote social recovery in people with substance dependency; 2017. p. 101-36. https:// www.ncnp.go.jp/nimh/yakubutsu/report/pdf/J_NMHS_2016.pdf (in Japanese). Accessed 20 Aug 2020.

5. Matsumoto T, Kobayashi O. What is the Japanese mental health service lacking for drug dependence rehabilitation? Nihon Arukoru Yakubutsu Igakkai Zasshi. 2008;43(3):172-87 (in Japanese).

6. Kaminer Y, Burleson JA, Goldberger R. Cognitive-behavioral coping skills and psychoeducation therapies for adolescent substance abuse. J Nerv Ment Dis. 2002;190(11):737-45. https://doi.org/10.1097/00005053-20021100000003.

7. DiClemente CC, Prochaska JO, Fairhurst SK, Velicer WF, Velasquez MM, Rossi JS. The process of smoking cessation: An analysis of precontemplation, contemplation, and preparation stages of change. J Consult Clin Psychol. 1991:59(2):295-304. https://doi.org/10.1037/0022-006X.59.2.295.

8. Litt MD, Kadden RM, Kabela-Cormier E, Petry NM. Changing network support for drinking: network support project 2-year follow-up. J Consult Clin Psychol. 2009;77(2):229-42. https://doi.org/10.1037/a0015252.
9. Williams AR, Olfson M, Galanter M. Assessing and improving clinical insight among patients "in denial". JAMA Psychiatry. 2015;72(4):303-4. https://doi. org/10.1001/jamapsychiatry.2014.2684.

10. Bartone PT, Hystad SW, Eid J, Brevik Jl. Psychological hardiness and coping style as risk/resilience factors for alcohol abuse. Mil Med. 2012;177(5):517-24. https://doi.org/10.7205/MILMED-D-11-00200.

11. Rutter M. Resilience, competence, and coping. Child Abuse Negl. 2007;31(3): 205-9. https://doi.org/10.1016/j.chiabu.2007.02.001.

12. Collishaw S, Pickles A, Messer J, Rutter M, Shearer C, Maughan B. Resilience to adult psychopathology following childhood maltreatment: evidence from a community sample. Child Abuse Negl. 2007;31(3):211-29. https://doi. org/10.1016/j.chiabu.2007.02.004.

13. Dyer JG, McGuinness TM. Resilience: analysis of the concept. Arch Psychiatr Nurs. 1996;10(5):276-82. https://doi.org/10.1016/S0883-9417(96)80036-7.

14. American Psychological Association. What is resilience? The Road to Resilience. 2016. https://www.apa.org/helpcenter/road-resilience. Accessed 20 Aug 2020.

15. Luthar SS, Cicchetti D, Becker B. The construct of resilience: a critical evaluation and guidelines for future work. Child Dev. 2000;71(3):543-62. https://doi.org/10.1111/1467-8624.00164.

16. Hirano M. Review of resilience from the viewpoints of its innate and acquired aspects. Bull Graduate School Educ Univ Tokyo. 2012;52:411-7 (in Japanese).

17. Khantzian EJ. Understanding addictive vulnerability: An evolving psychodynamic perspective. Neuropsychoanalysis. 2003;5(1):5-21. https:// doi.org/10.1080/15294145.2003.10773403.

18. Alexander AC, Ward KD. Understanding postdisaster substance use and psychological distress using concepts from the self-medication hypothesis and social cognitive theory. J Psychoactive Drugs. 2018;50(2):177-86. https:// doi.org/10.1080/02791072.2017.1397304.

19. Bickel WK, Mellis AM, Snider SE, Athamneh LN, Stein JS, Pope DA. 21st century neurobehavioral theories of decision making in addiction. Rev Eval Pharmacol Biochem Behav. 2018;164:4-21. https://doi.org/10.1016/j.pbb.201 7.09.009.

20. Yang C, Zhou Y, Cao Q, Xia M, An J. The relationship between self-control and self-efficacy among patients with substance use disorders: resilience and self-esteem as mediators. Front Psychiatry. 2019;10:388. https://doi.org/1 0.3389/fpsyt.2019.00388

21. Yang C, Xia M, Han M, Liang Y. Social support and resilience as mediators between stress and life satisfaction among people with substance use disorder in China. Front Psychiatry. 2018;9:436. https://doi.org/10.3389/ fpsyt.2018.00436.

22. Bertrand K, Richer I, Brunelle N, Beaudoin I, Lemieux A, Ménard JM. Substance abuse treatment for adolescents: how are family factors related to substance use change? J Psychoactive Drugs. 2013;45(1):28-38. https:// doi.org/10.1080/02791072.2013.763560.

23. Mallow AJ. Self-disclosure. Reconciling psychoanalytic psychotherapy and alcoholics anonymous philosophy. J Subst Abus Treat. 1998;15(6):493-8. https://doi.org/10.1016/S0740-5472(97)00291-2.

24. Galanter M, Dermatis H, Post S, Sampson C. Spirituality-based recovery from drug addiction in the twelve-step fellowship of narcotics anonymous. J Addict Med. 2013;7(3):189-95. https://doi.org/10.1097/ADM.0b013e31828a02 65.

25. Anthony WA. Recovery from mental illness: the guiding vision of the menta health service system in the 1990s. Psychosoc Rehabil J. 1993;16:11-23.

26. Yamashita A, Yoshioka SI. Resilience associated with self-disclosure and relapse risks in patients with alcohol use disorders. Yonago Acta Med. 2016; 59:279-87.

27. Hirano M. Validity of the bidimensional resilience scale for junior high and high school students: An analysis using the twin method. Jpn J Pers. 2011; 20(1):50-2 (in Japanese). https://doi.org/10.2132/personality.20.50.

28. Hirano M. A study of the classification of resilience factors: development of the bidimensional resilience scale (BRS). Jpn J Pers. 2010;19(2):94-106 (in Japanese). https://doi.org/10.2132/personality.19.94.

29. Ogai Y, Haraguchi A, Kondo A, Yoko I, Mitsuru U, Hirotsugu K, et al. Development and validation of the stimulant relapse risk scale for drug abusers in Japan. Drug Alcohol Depend. 2007;88(2-3):174-81. https://doi. org/10.1016/j.drugalcdep.2006.10.005

30. Belcher AM, Volkow ND, Moeller FG, Ferré S. Personality traits and vulnerability or resilience to substance use disorders. Trends Cogn Sci. 2014; 18(4):211-7. https://doi.org/10.1016/j.tics.2014.01.010. 
31. Rutter M. Psychosocial resilience and protective mechanisms. Am J Orthop. 1987:57:316-31.

32. Priddy SE, Howard MO, Hanley AW, Riquino MR, Friberg-Felsted K, Garland EL. Mindfulness meditation in the treatment of substance use disorders and preventing future relapse: neurocognitive mechanisms and clinical implications. Subst Abus Rehabil. 2018;9:103-14. https://doi.org/10.2147/SAR. S145201.

33. Shoptaw S, Rawson RA, McCann MJ, Obert JL. The matrix model of outpatient stimulant abuse treatment: evidence of efficacy. J Addict Dis. 1994;13(4):129-41. https://doi.org/10.1300/j069v13n04_02.

34. Masten AS. Ordinary magic. Resilience processes in development. Am Psychol. 2001;56(3):227-38. https://doi.org/10.1037/0003-066X.56.3.227.

35. Johnson K, Bryant DD, Collins DA, Noe TD, Strader TN, Berbaum M. Preventing and reducing alcohol and other drug use among high-risk youths by increasing family resilience. Soc Work. 1998;43(4):297-308. https:// doi.org/10.1093/sw/43.4.297.

36. Dunn KE, Fingerhood M, Wong CJ, Svikis DS, Nuzzo P, Silverman K. Employment-based abstinence reinforcement following inpatient detoxification in HIV-positive opioid and/or cocaine-dependent patients. Exp Clin Psychopharmacol. 2014;22(1):75-85. https://doi.org/10.1037/a0034 863.

37. Yamashita A, Oriyama S, Watanabe K. Factors that influence the drug stopping of patients with drug dependence: in relation to their quality of life and self-esteem. J Japanese Soc Nurs Res. 2013;36:47-57 (in Japanese).

38. Ragins M. In: Mental Health America of Los Angeles, editor. Medical Director MHA Village. A road to recovery. Los Angeles: Mental Health America of Los Angeles; 2010.

39. Bowden K, Goodman D. Barriers to employment for drug dependent postpartum women. Work. 2015;50(3):425-32. https://doi.org/10.3233/ WOR-141951.

40. Mills H, Mulfinger N, Raeder S, Rüsch N, Clements H, Scior K. Self-help interventions to reduce self-stigma in people with mental health problems: a systematic literature review. Psychiatry Res. 2020;284:1 12702. https://doi. org/10.1016/j.psychres.2019.112702.

41. Sudraba V, Millere I, Rancans E. Effectiveness of self-help groups and psychotherapy: self-assessment of patients with substance use disorders. Medicina (Kaunas). 2012:48:544-51.

42. Marsden J, Anders P, Clark H, Colocassis K, Eastwood B, Knight J, et al. Protocol for a multi-Centre, definitive randomised controlled trial of the effectiveness of individual placement and support for employment support among people with alcohol and drug dependence. Trials. 2020;21(1):167. https://doi.org/10.1186/s13063-020-4099-4

\section{Publisher's Note}

Springer Nature remains neutral with regard to jurisdictional claims in published maps and institutional affiliations.

Ready to submit your research? Choose BMC and benefit from:

- fast, convenient online submission

- thorough peer review by experienced researchers in your field

- rapid publication on acceptance

- support for research data, including large and complex data types

- gold Open Access which fosters wider collaboration and increased citations

- maximum visibility for your research: over $100 \mathrm{M}$ website views per year

At $\mathrm{BMC}$, research is always in progress.

Learn more biomedcentral.com/submissions 